\title{
Green One-Pot Synthesis of Coumarin-Hydroxybenzohydrazide Hybrids and Their Antioxidant Potency
}

\author{
Marko R. Antonijević ${ }^{1,2}$, Dušica M. Simijonović ${ }^{1} \mathbb{1}$, Edina H. Avdović ${ }^{1, *}{ }^{1}$, Andrija Ćirić ${ }^{2}$, Zorica D. Petrović ${ }^{2}$, \\ Jasmina Dimitrić Marković ${ }^{3}$, Višnja Stepanić ${ }^{4}$ and Zoran S. Markovićc ${ }^{1, *}$ \\ 1 Department of Science, Institute for Information Technologies, University of Kragujevac, Jovana Cvijića bb, \\ 34000 Kragujevac, Serbia; mantonijevic@uni.kg.ac.rs (M.R.A.); dusicachem@kg.ac.rs (D.M.S.) \\ 2 Department of Chemistry, Faculty of Science, University of Kragujevac, Radoja Domanovića 12, \\ 34000 Kragujevac, Serbia; andrija.ciric@pmf.kg.ac.rs (A.Ć.); zorica.petrovic@pmf.kg.ac.rs (Z.D.P.) \\ 3 Faculty of Physical Chemistry, University of Belgrade, Studentski trg 12-16, 11000 Belgrade, Serbia; \\ markovich@ffh.bg.ac.rs \\ 4 Ruđer Bošković Institute, Bijenička Cesta 54, 10000 Zagreb, Croatia; visnja.stepanic@irb.hr \\ * Correspondence: edina.avdovic@pmf.kg.ac.rs (E.H.A.); zmarkovic@uni.kg.ac.rs (Z.S.M.); \\ Tel.: +381-34-610-01-95 (Z.S.M.)
}

Citation: Antonijević, M.R.; Simijonović, D.M.; Avdović, E.H.; Ćirić, A.; Petrović, Z.D.; Marković, J.D.; Stepanić, V.; Marković, Z.S. Green One-Pot Synthesis of Coumarin-Hydroxybenzohydrazide Hybrids and Their Antioxidant Potency. Antioxidants 2021, 10, 1106. https://doi.org/10.3390/ antiox10071106

Academic Editors: Irene Dini and Domenico Montesano

Received: 7 June 2021

Accepted: 7 July 2021

Published: 10 July 2021

Publisher's Note: MDPI stays neutral with regard to jurisdictional claims in published maps and institutional affiliations.

Copyright: (C) 2021 by the authors Licensee MDPI, Basel, Switzerland. This article is an open access article distributed under the terms and conditions of the Creative Commons Attribution (CC BY) license (https:/ / creativecommons.org/licenses/by/ $4.0 /)$.

\begin{abstract}
Compounds from the plant world that possess antioxidant abilities are of special importance for the food and pharmaceutical industry. Coumarins are a large, widely distributed group of natural compounds, usually found in plants, often with good antioxidant capacity. The coumarin-hydroxybenzohydrazide derivatives were synthesized using a green, one-pot protocol. This procedure includes the use of an environmentally benign mixture (vinegar and ethanol) as a catalyst and solvent, as well as very easy isolation of the desired products. The obtained compounds were structurally characterized by IR and NMR spectroscopy. The purity of all compounds was determined by HPLC and by elemental microanalysis. In addition, these compounds were evaluated for their in vitro antioxidant activity. Mechanisms of antioxidative activity were theoretically investigated by the density functional theory approach and the calculated values of various thermodynamic parameters, such as bond dissociation enthalpy, proton affinity, frontier molecular orbitals, and ionization potential. In silico calculations indicated that hydrogen atom transfer and sequential proton loss-electron transfer reaction mechanisms are probable, in non-polar and polar solvents respectively. Additionally, it was found that the single-electron transfer followed by proton transfer was not an operative mechanism in either solvent. The conducted tests indicate the excellent antioxidant activity, as well as the low potential toxicity, of the investigated compounds, which makes them good candidates for potential use in food chemistry.
\end{abstract}

Keywords: coumarins; green synthesis; antioxidants; DFT

\section{Introduction}

The oxygen molecule is an important electron acceptor in metabolic processes in the cells of living organisms. It plays an important role in the cell's respiratory processes, especially in a process of oxidative phosphorylation. This molecule is included in almost all electron transfer processes in organisms, and is one of the key components of the electron-transport chain, which has a crucial role in energy production [1]. However, besides its many positive effects, as a result of its bi-radical properties, it also enables the formation of partially reduced chemical species known as reactive oxygen species (ROS), which can be involved in starting a chain reaction that could be potentially dangerous for the cell [2]. The production of ROS in the organism is a natural process that allows the immune system to remove foreign bodies from blood, manages cell-signaling, leads to acceleration of the aging process, etc. ROS are constantly forming within the cells upon exposure to drugs, air pollutants, ultraviolet rays, ionizing radiation, smoke, and some 
endogenous metabolites of the redox and respiratory chain during the transfer of electrons. Under normal conditions, the organism is capable of regulating the production of ROS in such a manner that damage caused by influences of chemical agents on healthy cells is reduced to a minimum. The human body has developed a complex defense system against oxidative stress that includes preventive, restorative, antioxidant mechanisms, and physiological defense [3]. The natural system of antioxidant protection includes enzymatic and non-enzymatic antioxidants. Enzymatic antioxidants consist of a limited number of proteins such as catalase, glutathione peroxidase, superoxide dismutase, along with some auxiliary enzymes. They work by converting reactive species into hydrogen peroxide and later into water, in the presence of cofactors such as copper, zinc, manganese, and iron. Another group of antioxidants can be divided into direct and indirect, depending on the mechanism of action. Direct-acting antioxidants are extremely important in the body's defense against oxidative stress. Most of them are taken into the body through diet, and only a small number are synthesized in the body itself. These include vitamins, polyphenols, carotenoids, etc. Most of the naturally occurring antioxidants are found in the plant world, often in plants used in traditional medicine. Extraction, identification, and evaluation of the biological activity of these compounds has been a hot topic in the last couple of decades [4-6].

Despite the great efforts of many researchers over many years, creating new and potent antioxidant agents, which will also satisfy other criteria, like solubility and selective biological activity/toxicity, is quite challenging. Coumarins are relatively simple, naturally occurring phenolic compounds consisting of fused $\gamma$-pyrone and benzene rings, along with the carbonyl group on the pyrone ring at position $\mathrm{C} 2$. They are found in some essential oils like lavender oil, cinnamon bark oil, and cassia leaf oil. They mostly occur in higher plants, in the fruits, followed by the roots, stems, and leaves. The most frequent source for human exposure to coumarins is certain types of cinnamon. Coumarins have important biological functions, such as growth regulation, respiratory control, protection against herbivores and microorganisms. Simple coumarins act as hormones and signaling molecules. Over the last decade, antioxidant, anti-inflammatory, anticoagulant, enzyme inhibitory, antimicrobial, and anticancer activities of coumarins have been widely investigated. Some of them, like novobiocin and armillarisin A (antibiotics), warfarin, phenprocoumon, and acenocoumarol (anticoagulants), and hymecromone (antispasmodic and choleretic) have been in clinical use for many years [7-15].

Synthetic coumarins have great potential for developing new compounds with the aforementioned desired activities. It is worth pointing out that the reactions regarding 3-acetyl-4-hydroxycoumarin and various benzoyl hydrazides have been described in only a few articles [16-18]. The synthesis of coumarin-hydrazide derivatives was achieved via condensation of 3-acetyl-4-hydroxycoumarin with appropriate hydrazides under reflux in $n$-propanol or by heating in ethanol and in the presence of acetic acid as catalyst. Additionally, in these studies, the isolated products were evaluated for their antioxidant, anti-LOX, and anticancer activity. The investigated compounds exhibited good to moderate cytotoxicity and anti-inflammatory activity, while the radical scavenging activity was bad.

The aim of this research is the synthesis of new coumarin hydroxybenzohydrazide derivatives with expected good antioxidant activity. For this synthesis green, simple and low-cost protocol was used. The synthesized compounds are structurally characterized, and their in vitro antiradical activity is investigated. Since they can be potent antioxidants, a theoretical investigation of the structure and reaction mechanisms involved in free radical scavenging is performed. DFT approach allowed the computation of various thermodynamic properties, such as bond dissociation enthalpy (BDE), proton affinity (PA), frontier molecular orbitals and HOMO-LUMO gap, and ionization potential (IP), to predict the mechanisms of antioxidative action. 


\section{Materials and Methods}

\subsection{Chemical Reagents and Instruments}

Chemicals (purity $>98 \%$ ) used for the synthesis were acquired from Merck, and vinegar (acetic acid $90 \mathrm{~g} / \mathrm{L}$ ) was purchased from the local market. Compounds 3-acetyl4-hydroxycoumarin (1) and hydrazides (2) were prepared according to the previously reported methods $[19,20]$. All chemicals used in HPLC analysis were HPLC grade.

IR spectroscopy was performed on a Perkin-Elmer Spectrum One FT-IR spectrometer using the $\mathrm{KBr}$ disc. The NMR spectra were recorded on a Varian Gemini spectrometer (200 MHz for ${ }^{1} \mathrm{H}$ and $50 \mathrm{MHz}$ for ${ }^{13} \mathrm{C}$ ) in DMSO- $d_{6}$. The UV-Vis measurements were recorded on Agilent Technologies, Cary 300 Series UV/Vis Spectrophotometer. Melting points were determined on a Mel-Temp capillary melting points apparatus, model 1001. Elemental microanalysis for carbon, hydrogen, and nitrogen was done in the Centre for Instrumental Analysis, at the Faculty of Chemistry, Belgrade. Elemental $(\mathrm{C}, \mathrm{H}, \mathrm{N})$ analysis of the samples was carried out on an Elemental analysis system VARIO EL III CHNOS, model-Elementar Analysensysteme $\mathrm{GmbH}$, 2003. To confirm the purity of isolated products, HPLC analyses were performed using an HPLC system (Shimadzu Prominence, Kyoto, Japan) with a PDA detector (SPD-M20A). The separation was carried out using a Hypersil Gold aQ C18 column $(150 \times 4.6 \mathrm{~mm}, 5 \mu \mathrm{m})$ at a flow rate of $1 \mathrm{~mL} / \mathrm{min}$. Mobile phases: (A) $0.1 \%$ formic acid in water, (B) $0.1 \%$ formic acid in acetonitrile. Gradient profile $0-2 \mathrm{~min} 2 \%$ B, $45 \mathrm{~min}$ $95 \%$ B.

\subsection{Synthesis of Coumarin-Hydroxybenzohydrazide Derivatives}

The starting compounds 3-acetyl-4-hydroxycoumarin (1) (1 mmoL) and benzoyl hydrazides (2) (1 mmoL), were dissolved in a mixture of vinegar and ethanol (1:1) $(20 \mathrm{~mL})$ and stirred at reflux for $5 \mathrm{~h}$. Reaction progress was monitored using thin-layer chromatography (TLC). When the reaction was completed, the resulting mixture was cooled to room temperature and the precipitate was collected by filtration. All of the coumarinhydroxybenzohydrazide products (3a-e) were characterized with melting points, ${ }^{1} \mathrm{H} N M R$, ${ }^{13} \mathrm{C}$ NMR, and IR spectra, as well as with elemental and HPLC analysis.

(E)-N'-(1-(2,4-dioxochroman-3-ylidene)ethyl)-2-hydroxybenzohydrazide (3a). Beige solid, m.p. $248-249{ }^{\circ} \mathrm{C}$; Isolated yield: $0.221 \mathrm{~g}(65.31 \%)$, HPLC purity: $91.44 \% ;{ }^{1} \mathrm{H}$ NMR $(200 \mathrm{MHz}$, DMSO- $\left.d_{6}\right) \delta: 15.95(\mathrm{~s}, 1 \mathrm{H}), 8.00(\mathrm{dd}, J=7.8,1.6 \mathrm{~Hz}, 1 \mathrm{H}), 7.87(\mathrm{dd}, J=7.8,1.7 \mathrm{~Hz}, 1 \mathrm{H}), 7.67$ $(\mathrm{m}, 1 \mathrm{H}), 7.53-7.40(\mathrm{~m}, 1 \mathrm{H}), 7.40-7.25(\mathrm{~m}, 2 \mathrm{H}), 7.07-6.90(\mathrm{~m}, 2 \mathrm{H}), 2.74(\mathrm{~s}, 3 \mathrm{H}) ;{ }^{13} \mathrm{C}$ NMR (50 MHz, DMSO- $\left.d_{6}\right) \delta: 178.8,170.5,164.3,161.5,157.5,153.1,134.3,134.1,129.9,125.7,123.9$, 119.6, 119.5, 117.1, 116.4, 116.3, 95.4, 17.6; IR (KBr): $3521(\mathrm{OH}), 3435,3267(\mathrm{NH}), 3049(=\mathrm{CH})$, 2930, $2862(\mathrm{CH}), 1692,1629,1608(\mathrm{C}=\mathrm{O}), 1547,1455(\mathrm{C}=\mathrm{C}), 1233(\mathrm{C}-\mathrm{O}) \mathrm{cm}^{-1} ; \mathrm{C}_{18} \mathrm{H}_{14} \mathrm{~N}_{2} \mathrm{O}_{5}$ $(\mathrm{FW}=338.32): \mathrm{C}, 63.90 ; \mathrm{N}, 8.28 ; \mathrm{H}, 4.17 \%$; found: $\mathrm{C}, 63.74 ; \mathrm{N}, 8.45 ; \mathrm{H}, 4.28 \%$.

(E)-N'-(1-(2,4-dioxochroman-3-ylidene)ethyl)-4-hydroxybenzohydrazide (3b).White solid, m.p. $264-265^{\circ} \mathrm{C}$; Isolated yield: $0.215 \mathrm{~g}(63.51 \%)$, HPLC purity: $97.79 \%$; ${ }^{1} \mathrm{H}$ NMR $(200 \mathrm{MHz}$, DMSO- $\left.d_{6}\right) \delta: 15.72(\mathrm{~s}, 1 \mathrm{H}), 11.56(\mathrm{~s}, 1 \mathrm{H}), 10.34(\mathrm{~s}, 1 \mathrm{H}), 7.99(\mathrm{dd}, J=7.8,1.6 \mathrm{~Hz}, 1 \mathrm{H}), 7.90-7.78$ $(\mathrm{m}, 2 \mathrm{H}), 7.73-7.57(\mathrm{~m}, 1 \mathrm{H}), 7.39-7.23(\mathrm{~m}, 2 \mathrm{H}), 6.96-6.85(\mathrm{~m}, 2 \mathrm{H}), 2.74(\mathrm{~s}, 3 \mathrm{H}) ;{ }^{13} \mathrm{C} \mathrm{NMR}$ $\left(50 \mathrm{MHz}, \mathrm{DMSO}-d_{6}\right) \delta: 179.2,171.8,164.6,161.6,161.5,153.2,134.3,130.1,125.7,123.9$, 121.6, 119.8, 116.4, 115.4, 95.3, 17.8; IR (KBr): $3565(\mathrm{OH}), 3435,3183(\mathrm{NH}), 3057(=\mathrm{CH}), 2964$, $2807(\mathrm{CH}), 1666,1639,1605(\mathrm{C}=\mathrm{O}), 1566,1490,1467(\mathrm{C}=\mathrm{C}), 1232(\mathrm{C}-\mathrm{O}) \mathrm{cm}^{-1} ; \mathrm{C}_{18} \mathrm{H}_{14} \mathrm{~N}_{2} \mathrm{O}_{5}$ $(\mathrm{FW}=338.32): \mathrm{C}, 63.90 ; \mathrm{N}, 8.28 ; \mathrm{H}, 4.17 \%$; found: $\mathrm{C}, 63.68 ; \mathrm{N}, 8.40 ; \mathrm{H}, 4.37 \%$.

(E)-N'-(1-(2,4-dioxochroman-3-ylidene)ethyl)-4-hydroxy-3-methoxybenzohydrazide (3c). Light yellow solid, m.p. $223-224{ }^{\circ} \mathrm{C}$; Isolated yield: $0.246 \mathrm{~g}(66.83 \%)$, HPLC purity: $98.50 \% ;{ }^{1} \mathrm{H}$ $\operatorname{NMR}\left(200 \mathrm{MHz}, \mathrm{DMSO}-d_{6}\right) \delta: 15.67(\mathrm{~s}, 1 \mathrm{H}), 11.55(\mathrm{~s}, 1 \mathrm{H}), 9.96(\mathrm{~s}, 1 \mathrm{H}), 8.00$ (dd, J = 7.8, $1.3 \mathrm{~Hz}, 1 \mathrm{H}), 7.95(\mathrm{~m}, 1 \mathrm{H}), 7.67(\mathrm{ddd}, J=8.1,7.4,1.7 \mathrm{~Hz}, 1 \mathrm{H}), 7.54-7.43(\mathrm{~m}, 2 \mathrm{H}), 7.32$ (ddd, $J=8.0,5.3,1.6 \mathrm{~Hz}, 2 \mathrm{H}), 6.92(\mathrm{~d}, J=11.3 \mathrm{~Hz}, 1 \mathrm{H}), 3.86(\mathrm{~s}, 3 \mathrm{H}), 2.75(\mathrm{~s}, 3 \mathrm{H}) ;{ }^{13} \mathrm{C} \mathrm{NMR}(50 \mathrm{MHz}$, DMSO- $d_{6}$ ) $\delta: 179.3,175.9,172.2,164.6,161.6,153.2,151.1,147.5,134.4,125.8,123.9,122.0$, $121.8,119.8,116.4,115.3,111.9,95.4,55.9,17.9 ; \mathrm{IR}(\mathrm{KBr}): 3524(\mathrm{OH}), 3388,3235(\mathrm{NH}), 3090$ $(=\mathrm{CH}), 2944,2782(\mathrm{CH}), 1675,1605,1591(\mathrm{C}=\mathrm{O}), 1527,1484,1410(\mathrm{C}=\mathrm{C}), 1221(\mathrm{C}-\mathrm{O}) \mathrm{cm}^{-1}$; $\mathrm{C}_{19} \mathrm{H}_{16} \mathrm{~N}_{2} \mathrm{O}_{6}(\mathrm{FW}=368.10): \mathrm{C}, 61.96 ; \mathrm{N}, 7.61 ; \mathrm{H}, 4.38 \%$; found: $\mathrm{C}, 61.62 ; \mathrm{N}, 7.43 ; \mathrm{H}, 4.17 \%$. 
(E)-N'-(1-(2,4-dioxochroman-3-ylidene)ethyl)-2,3-dihydroxybenzohydrazide (3d). Beige solid, m.p. $245-247^{\circ} \mathrm{C}$; Isolated yield: $0.223 \mathrm{~g}$ (62.85\%), HPLC purity: $99.10 \%$; ${ }^{1} \mathrm{H} \mathrm{NMR}(200 \mathrm{MHz}$, DMSO- $\left.d_{6}\right) \delta: 15.88(\mathrm{~s}, 1 \mathrm{H}), 8.00(\mathrm{dd}, J=7.8,1.4 \mathrm{~Hz}, 1 \mathrm{H}), 7.76-7.58(\mathrm{~m}, 1 \mathrm{H}), 7.47-7.20(\mathrm{~m}$, $3 \mathrm{H}), 7.02(\mathrm{dd}, J=7.8,1.6 \mathrm{~Hz}, 1 \mathrm{H}), 6.80(\mathrm{t}, J=7.9 \mathrm{~Hz}, 1 \mathrm{H}), 2.73(\mathrm{~s}, 3 \mathrm{H}) ;{ }^{13} \mathrm{C} \mathrm{NMR}(50 \mathrm{MHz}$, DMSO-d $)) \delta: 178.9,171.0,165.5,161.5,153.2,147.2,146.2,134.4,125.7,124.0,119.6,119.4$, 119.1, 119.1, 116.4, 116.2, 95.5, 17.6; IR (KBr): $3498(\mathrm{OH}), 3386,3269(\mathrm{NH}), 3050(=\mathrm{CH})$, 2964, 2863 (CH), 1703, 1659, 1609 (C=O), 1583, 1524, 1484, 1466 (C=C), $1222(\mathrm{C}-\mathrm{O}) \mathrm{cm}^{-1}$; $\mathrm{C}_{18} \mathrm{H}_{14} \mathrm{~N}_{2} \mathrm{O}_{6}(\mathrm{FW}=354.32):$ C, 61.02; N, 7.91; H, 3.98\%; found: $\mathrm{C}, 61.22 ; \mathrm{N}, 7.79 ; \mathrm{H}, 3.67 \%$.

(E)-N'-(1-(2,4-dioxochroman-3-ylidene)ethyl)-3,4-dihydroxybenzohydrazide (3e). Beige solid, m.p. $255-257^{\circ} \mathrm{C}$; Isolated yield: $0.233 \mathrm{~g}$ (65.71\%), HPLC purity: $97.46 \%$; ${ }^{1} \mathrm{H} \mathrm{NMR}(200 \mathrm{MHz}$, DMSO- $\left.d_{6}\right) \delta: 15.71(\mathrm{~s}, 1 \mathrm{H}), 11.51(\mathrm{~s}, 1 \mathrm{H}), 9.86(\mathrm{~s}, 1 \mathrm{H}), 9.45(\mathrm{~s}, 1 \mathrm{H}), 7.99$ (dd, J = 7.9, $1.5 \mathrm{~Hz}$, $1 \mathrm{H}), 7.66(\mathrm{ddd}, J=8.1,7.4,1.7 \mathrm{~Hz}, 1 \mathrm{H}), 7.44-7.14(\mathrm{~m}, 4 \mathrm{H}), 6.87(\mathrm{~d}, J=8.1 \mathrm{~Hz}, 1 \mathrm{H}), 2.73(\mathrm{~s}$, $3 \mathrm{H}) ;{ }^{13} \mathrm{C}$ NMR $\left(50 \mathrm{MHz}, \mathrm{DMSO}-d_{6}\right) \delta: 179.2,171.6,164.7,161.6,153.2,150.1,145.3,134.3$, $125.7,123.9,121.9,120.3,119.8,116.4,115.4,115.4,95.3,17.8 ; \mathrm{IR}(\mathrm{KBr}): 3478(\mathrm{OH}), 3419,3156$ (NH), 3066 (=CH), 2973 (CH), 1668, 1641, 1602 (C=O), 1568, 1489, 1457 (C=C), 1222 (C-O) $\mathrm{cm}^{-1} . \mathrm{C}_{18} \mathrm{H}_{14} \mathrm{~N}_{2} \mathrm{O}_{6}(\mathrm{FW}=354.32): \mathrm{C}, 61.02 ; \mathrm{N}, 7.91 ; \mathrm{H}, 3.98 \%$; found: $\mathrm{C}, 61.37 ; \mathrm{N}, 7.73$; $\mathrm{H}, 3.69 \%$.

\subsection{DPPH Radical Scavenging Assay}

The free radical scavenging activities of obtained products were determined by 2,2diphenyl-1-picrylhydrazyl (DPPH) assay [21]. In detail, the tested compounds (20 $\mu \mathrm{L}$ of different concentrations dissolved in DMSO and $980 \mathrm{~mL}$ of methanol) were mixed with an equal volume of the solution of DPPH in methanol $(0.05 \mathrm{mM})$. The prepared samples were shaken well and left at room temperature in the dark for 20 and $60 \mathrm{~min}$. After the incubation period absorbance was determined at $517 \mathrm{~nm}$ by using the methanol as a blank control. All tests were run in triplicate and averaged. Nordihydroguaiaretic acid (NDGA) and quercetin were used as positive controls. For products that exert good activity, $\mathrm{IC}_{50}$ values were determined. Detailed calculations of $\mathrm{IC}_{50}$ value for the most active compound is given in the Supplementary Material. The results are presented as mean \pm SD. For calculation of the stoichiometric factor $[22,23]$, the following equation was used:

$$
\text { stoichiometric factor }=\frac{[D P P H]_{0}}{\left(2 \times I C_{50}\right)}
$$

\subsection{Computational Methods}

The calculations were carried out by employing the Gaussian09 software package [24]. For optimization of neutral molecules, the corresponding radicals, anions, and radical cations quantum chemical calculations based on density functional theory (DFT) were used. Since it has been shown that the M062-X method well describes short-range and medium-range intramolecular and intermolecular interactions $(<500 \mathrm{pm})$ [25], the M06-2X method is applied in combination with $6-311++G(d, p)$ basis set. This theoretical model is suitable for thermodynamic and kinetic investigation of reaction mechanisms of examined compounds with free radicals [22,26]. All investigated structures were reoptimized in methanol $(\varepsilon=32.61)$, and benzene $(\varepsilon=2.27)$. The solvent effect was included by the Conductor-like Polarizable Continuum Model (CPCM) [27], without any geometrical constraints. Solvents were selected to simulate the polar and non-polar environments, as well as conditions of experimental measurements.

Three antioxidant mechanisms were selected for the evaluation of the antioxidant activity: Hydrogen Atom Transfer (HAT), Single-Electron Transfer followed by Proton Transfer (SET-PT), and Sequential Proton Loss-Electron Transfer (SPLET) [28-31].

The abstraction of hydrogen atoms can be described by two mechanisms, HAT and Proton-Coupled Electron Transfer (PCET) [29]. The HAT mechanism is defined as the simultaneous transfer of an electron and a proton between the donor and acceptor. On the other hand, the PCET mechanism involves a significant redistribution of molecular 
charge, during the transfer of hydrogen atoms. In this study, only the HAT mechanism was considered because only thermodynamic parameters were used to test antioxidant capacity. It should be noted that both reaction pathways are necessary for the kinetic examination of the mechanisms of antioxidant activity. In the HAT mechanism, the homolytic cleavage of the $\mathrm{O}-\mathrm{H}$ bond occurs leading to the separation between radical species $\left(\mathrm{Ar}-\mathrm{O}^{\bullet}\right)$ and a hydrogen atom (Equation (1)) [30,31].

$$
\mathrm{Ar}-\mathrm{OH} \rightarrow \mathrm{Ar}-\mathrm{O}^{\bullet}+\mathrm{H}^{\bullet}
$$

The SET-PT mechanism is a two-step process that includes electron loss from a molecule and generation of the radical cation $\left(\mathrm{Ar}-\mathrm{OH}^{+\bullet}\right)$, which in the second step loses protons (Equation (2a,b)).

$$
\begin{aligned}
& \mathrm{Ar}-\mathrm{OH} \rightarrow \mathrm{Ar}-\mathrm{OH}^{\bullet+}+\mathrm{e}^{-} \\
& \mathrm{Ar}-\mathrm{OH}^{\bullet+} \rightarrow \mathrm{Ar}-\mathrm{O}^{\bullet}+\mathrm{H}^{+}
\end{aligned}
$$

The SPLET mechanism is also a two-step mechanism. In the first step, an anion (Ar$\mathrm{O}^{-}$) is formed from the antioxidant molecule, while the corresponding radical is formed after the electron transfer in the second step of this mechanism (Equation $(3 a, b)$ ).

$$
\begin{aligned}
& \mathrm{Ar}-\mathrm{OH} \rightarrow \mathrm{Ar}^{-} \mathrm{O}^{-}+\mathrm{H}^{+} \\
& \mathrm{Ar}_{-} \mathrm{O}^{-} \rightarrow \mathrm{Ar}-\mathrm{O}^{\bullet}+\mathrm{e}^{-}
\end{aligned}
$$

The thermodynamic parameters governing the mentioned antioxidative mechanisms are BDE (Bond Dissociation Enthalpy) describing HAT, PA (Proton Affinity), and ETE (Electron Transfer Enthalpy) describing SPLET, and IP (Ionization Potential) and PDE (Proton Dissociation Enthalpy) describing SET-PT mechanism. The contribution of these parameters was calculated from the enthalpies of the optimized chemical species using the following equations [32,33]:

$$
\begin{gathered}
\mathrm{BDE}=H\left(\mathrm{Ar}-\mathrm{O}^{\bullet}\right)+H\left(\mathrm{H}^{\bullet}\right)-H(\mathrm{Ar}-\mathrm{OH}) \\
\mathrm{IP}=H\left(\mathrm{Ar}-\mathrm{OH}^{\bullet+}\right)+H\left(\mathrm{e}^{-}\right)-H(\mathrm{Ar}-\mathrm{OH}) \\
\mathrm{PDE}=H\left(\mathrm{Ar}-\mathrm{O}^{\bullet}\right)+H\left(\mathrm{H}^{+}\right)-H\left(\mathrm{Ar}-\mathrm{OH} \mathrm{H}^{\bullet+}\right) \\
\mathrm{PA}=H\left(\mathrm{Ar}-\mathrm{O}^{-}\right)+H\left(\mathrm{H}^{+}\right)-H(\mathrm{Ar}-\mathrm{OH}) \\
\mathrm{ETE}=H\left(\mathrm{Ar}-\mathrm{O}^{\bullet}\right)+H\left(\mathrm{e}^{-}\right)-H\left(\mathrm{Ar}-\mathrm{O}^{-}\right)
\end{gathered}
$$

All reaction enthalpies used in the equations were calculated at $298 \mathrm{~K}$. The calculated enthalpy values of the solvated proton, $H\left(\mathrm{H}^{+}\right)$and electron, $H\left(\mathrm{e}^{-}\right)$, for the M062-X method in benzene $\left(-856.9\right.$ and $\left.-11.9 \mathrm{~kJ} \mathrm{moL}^{-1}\right)$ and methanol $\left(-1010.5\right.$ and $\left.-93.5 \mathrm{~kJ} \mathrm{moL}^{-1}\right)$ were taken from the literature [28,34].

The free radical scavenging potency of the synthesized coumarin derivatives toward the DPPH radical was investigated in two different solvents: benzene and methanol. Mechanisms of radical scavenging activity are described by Equations (1s)-(5s), given in the Supplementary Material. Thermodynamic parameters of the investigated mechanisms were calculated according to Equations (6s)-(10s) from Supplementary material.

\section{Results and Discussion}

\subsection{Synthesis}

The synthesis of coumarin-hydroxybenzohydrazide derivatives (3) was achieved by treatment of 3-acetyl-4-hydroxycoumarin (1) with corresponding benzoyl hydrazides (2a-e), Scheme 1. The reaction medium for these reactions was a mixture of vinegar and ethanol (1:1). This medium provided good solubility of the reactants and acted as a catalyst. The coumarin-hydroxybenzohydrazide derivatives 3a-e were obtained in moderate yields under reflux for $5 \mathrm{~h}$. All products 3a-e were precipitated during the reaction and isolated 
by filtration. Three of five obtained products $(\mathbf{3 c}-\mathbf{e})$ are reported in this study for the first time.

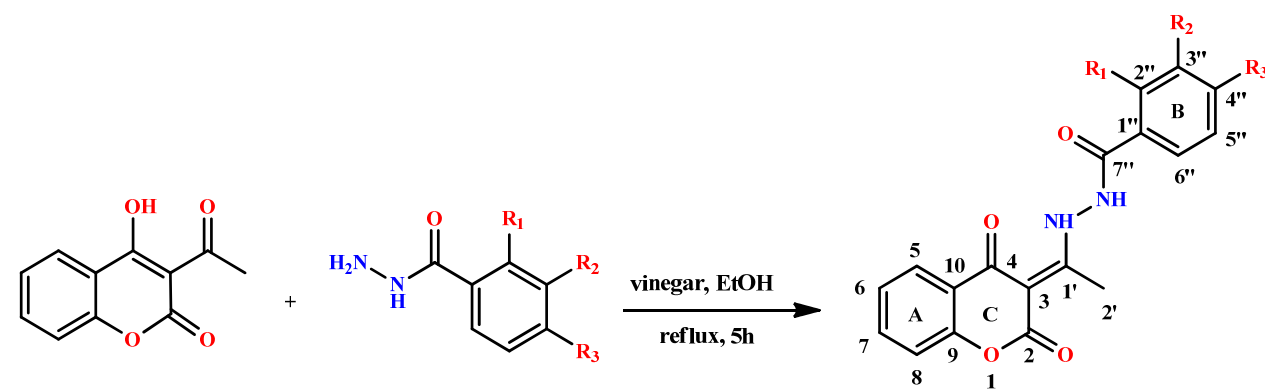

(1)

(2)

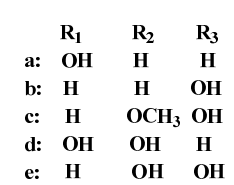

(3)

Scheme 1. Synthesis of coumarin-hydroxybenzohydrazide derivatives.

The synthesized coumarin-hydroxybenzohydrazide derivatives (3) were characterized using IR, ${ }^{1} \mathrm{H}$ and ${ }^{13} \mathrm{C}$ NMR spectroscopy, as well as with melting points. The purity of all isolated compounds was determined by HPLC and elemental analysis. The coumarinhydroxybenzohydrazide derivatives (3) were obtained in yields $62.85-66.83 \%$ and with HPLC purity in the range $91.44-99.10 \%$, Table 1 . HPLC data and chromatograms can be found in Supplementary Material, Tables S1-S5 and Figures S11-S15, respectively.

Table 1. Isolated yield and HPLC purity of synthesized coumarin-hydroxybenzohydrazide derivatives 3.

\begin{tabular}{cccc}
\hline Entry & Compound & Isolated Yield (\%) & HPLC Purity (\%) \\
\hline 1 & $3 \mathrm{a}$ & 65.31 & 91.44 \\
2 & $3 \mathrm{~b}$ & 63.51 & 97.79 \\
3 & $3 \mathrm{c}$ & 66.83 & 98.50 \\
4 & $3 \mathrm{~d}$ & 62.85 & 99.10 \\
5 & $3 \mathrm{e}$ & 65.71 & 97.46 \\
\hline
\end{tabular}

The 2,4-dione tautomeric form of these derivatives was assumed on the basis of the obtained spectroscopy data and X-ray structure which was determined for a similar type of compounds in our previous studies [35-37].

All synthesized compounds were characterized by IR spectroscopy. The obtained spectra are very similar to each other. In all spectra, bands of about $3500 \mathrm{~cm}^{-1}$ belonging to phenolic $\mathrm{OH}$ groups are observed, while bands of $\mathrm{NH}$ groups appear at lower wavenumbers, in the range of $3200-3400 \mathrm{~cm}^{-1}$. Bands in the region $1700-1600 \mathrm{~cm}^{-1}$ are assigned to different carbonyl groups. The stretching vibrations corresponding to the $\mathrm{C}-\mathrm{O}$ group were identified between 1220 and $1230 \mathrm{~cm}^{-1}$.

The NMR spectra of coumarin-hydroxybenzohydrazide derivatives presented in the Supplementary Material (Figures S1-S10) are in good agreement with the proposed structures. In the ${ }^{1} \mathrm{H}$ NMR spectra of all obtained compounds (3a-e) characteristic singlets positioned at 2.73-2.75 ppm are assigned to the protons of the methyl group in position C2'. In addition, the broad singlet appearing in the $9.45-10.34 \mathrm{ppm}$ range is assigned to phenolic protons, and the singlets positioned at a higher chemical shift, between 11.32-11.56 and 15.67-15.95 ppm, are assigned to two NH groups. The NMR spectra clearly show multiple resonance maxima of aromatic protons of the 2,4-dioxochroman and benzoyl moieties in the range of $6.80-8.00 \mathrm{ppm}$. In addition, the singlet at $3.86 \mathrm{ppm}$ in the spectrum of 
compound $3 \mathrm{c}$ is assigned to the proton of the methoxy group attached to the aromatic ring of the hydrazide moiety.

In the ${ }^{13} \mathrm{C}$ NMR spectra of compound 3a-e, the peak at about $18 \mathrm{ppm}$ was assigned to the carbon atom of the methyl group in position $\mathrm{C}^{\prime}$. The peak at about $95 \mathrm{ppm}$ is attributed to the $\mathrm{C} 3$ atom. The aromatic carbons of both parts have resonance maxima in the 112-153 ppm region. The resonance maxima with the highest chemical shifts, at about $179 \mathrm{ppm}$, originate from carbon atoms of the C4-carbonyl group, while the signals of the amide and lactone carbonyl groups occur at lower chemical shifts, at about 161-165 ppm. The $\mathrm{C} 1$ atom showed a resonance in the range of $171-176 \mathrm{ppm}$.

The predicted mechanism of synthesis of new coumarin-hydrazide hybrids is presented in Scheme 2. The first step of the reaction is the nucleophilic attack of the hydrazide on the carbon of the carbonyl group of coumarin (I), whereby intermediate (II) is formed. In the next step, the proton from the $\mathrm{NH}_{2}$ group is transferred to a partially negative oxygen atom of the $\mathrm{C}=\mathrm{O}$ group, which is followed by the formation of a hemiaminal (III). In the further course of the reaction, the protonation of the -OH group takes place in the presence of acetic acid, which is followed by releasing of the water molecules (IV). Deprotonation of the iminium ion (V) leads to the formation of the enol form of the coumarin-hydroxybenzohydrazide hybrids (VI). In the last step, by acid-catalyzed keto-enol tautomerization, a more stable keto form (VII) is obtained. The confirmation of this reaction path is supported by the fact that ${ }^{1} \mathrm{H}$ NMR spectra for all obtained compounds showed signals at about $15 \mathrm{ppm}$, which originate from the proton-NH group [35-37].

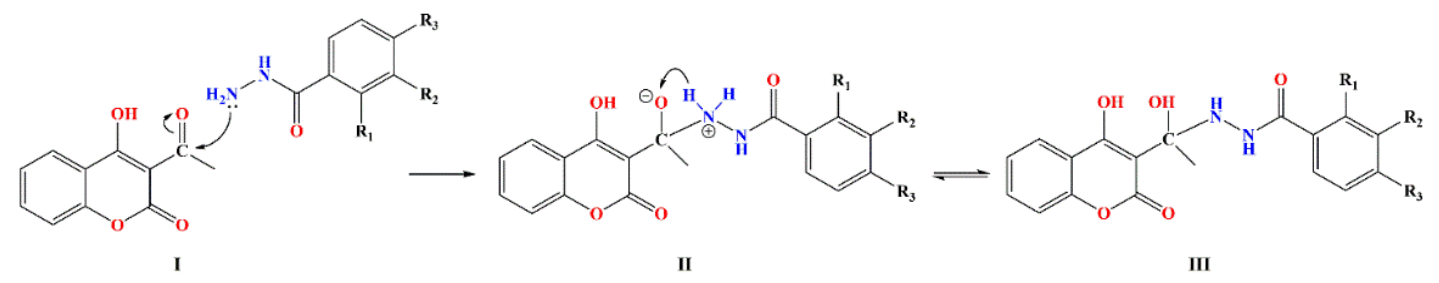<smiles>CC(=O)NC(C)=C1C(=O)Oc2ccccc2C1=O</smiles>

VII

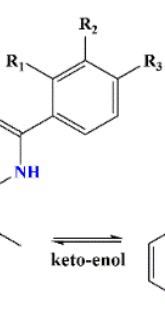

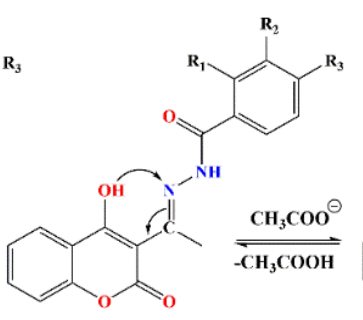

VI

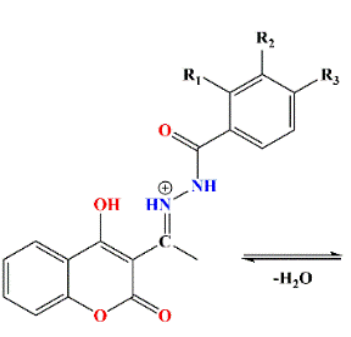

$\mathrm{v}$

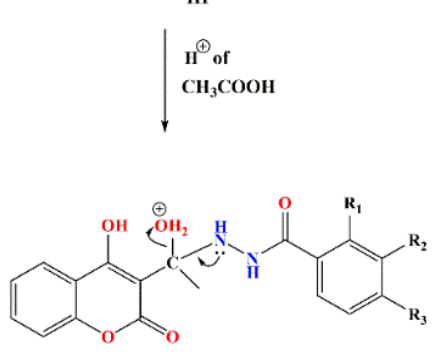

IV

Scheme 2. The suggested mechanism of the formation of coumarin-hydroxybenzohydrazide hybrids by the reaction between 3-acetyl-4-hydroxycoumarin and benzoyl hydrazides.

\subsection{In Vitro Antioxidative Activity of Tested Compounds}

The results of the in vitro DPPH test are presented in Table 2. The obtained results show that two out of five investigated compounds, $\mathbf{3 d}$, and 3e, expressed high antioxidant activity, with $\mathrm{IC}_{50}$ values of 2.9 and $12.9 \mu \mathrm{M}$, respectively. It should be mentioned that the compound 3d reduced DPPH well and exhibited high activity, slightly lower than the reference compounds NDGA and quercetin. The compound $3 \mathbf{e}$ also showed high antioxidative activity, a little bit lower than compound 3d. Namely, based on the obtained results, the new compounds $\mathbf{3 d}$ and $\mathbf{3 e}$ can be considered good antioxidants. Additionally, the stoichiometric factor (SF) of $\mathbf{3 d}$, which is equal to 4.4, indicates very good antioxidative ability, taking into account the fact that significant radical scavengers have SF bigger than $2[22,23,38,39]$. 
Table 2. In vitro DPPH antioxidant activity of products 3 and reference compounds (\%, $\mathrm{IC}_{50}$ and SF values).

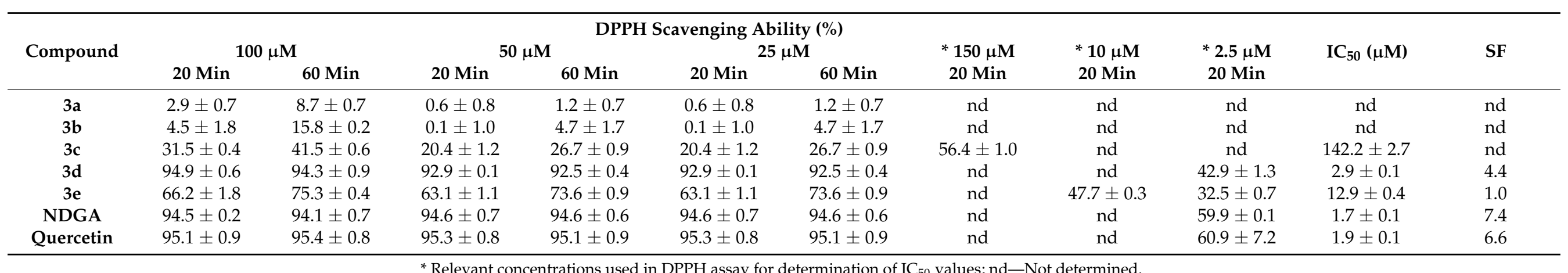

* Relevant concentrations used in DPPH assay for determination of $\mathrm{IC}_{50}$ values; nd-Not determined. 
The obtained results for compounds $3 a-c$ revealed that the presence of only one phenolic $\mathrm{OH}$ group had no significant effect on the DPPH radical scavenging activity. However, for compounds $\mathbf{3 d}$ and $\mathbf{3 e}$, with additional phenolic $\mathrm{OH}$ groups in neighboring positions, a significant improvement of antioxidative activity was observed. This is in agreement with the fact that the pronounced antioxidative capacity of compounds with catechol moiety stems from resonance and electron-donating effects of these groups, which increase the stability of the formed phenoxy radical. In these compounds, the hydroxy group supports the homolytic cleavage of the neighboring $\mathrm{O}-\mathrm{H}$ bond and enables the formation of a hydrogen bond with formed phenoxy radical [40-42].

In addition, appropriate in silico methods were used to determine the most likely mechanism of radical scavenging activity of coumarin-hydroxybenzohydrazide derivatives (3).

\subsection{Thermodynamic Parameters of Antioxidative Activity}

Geometry optimization of the examined compounds was performed using the M062X/ $6-311++G(d, p)$ model. The most stable conformations of 3a-e are shown in Figure S16. The obtained values for bond lengths, bond angles, and dihedral angles are shown in Tables S8S10. To confirm that the obtained geometries were the minimums on the potential energy surface, the vibration frequencies were calculated at the same theoretical level. This means that the corresponding stationary points were without negative eigenvalues in the force constant matrix. From the optimized molecular structure of the five coumarin derivatives, it can be seen that the N-N bond is a partial double bond that exists in all compounds and provides delocalization of the $\pi$-electron between the coumarin base and the aromatic ring (B), which contributes to the stabilization of the formed radicals after $\mathrm{H}$-abstraction. Compared to all phenol-hydroxy and amino groups on all considered molecules 3a-e, the bond length $\mathrm{C}^{\prime} \mathrm{N}-\mathrm{H}$ is noticeably longer than $\mathrm{C} 7^{\prime \prime} \mathrm{N}-\mathrm{H}$. This may be associated with a ketone group at the $\mathrm{C} 4$ position that forms an $\mathrm{HB}$ between $\mathrm{C} 1^{\prime} \mathrm{NH}$ and $\mathrm{O} 4$, resulting in an extension of the bond length of the $\mathrm{C} 1^{\prime} \mathrm{N}-\mathrm{H}$ bond. Alongside this hydrogen bond, compounds $3 \mathbf{c}-\mathbf{e}$ are capable of establishing additional hydrogen bonds, due to the fact that they possess additional $\mathrm{OH}$ groups in different positions. The additional hydrogen bond in $3 \mathrm{c}$ is located between the $\mathrm{C}^{\prime \prime}-\mathrm{OH}$ and $\mathrm{C}^{\prime \prime}-\mathrm{OCH}_{3}$ groups, while there are three $\mathrm{HB}$ in $\mathbf{3 d}$, from which two are formed between $\mathrm{C}^{\prime \prime}-\mathrm{OH}$, the adjacent carbonyl group and $\mathrm{C}^{\prime \prime}$-OH group. There are only two HBs in compound 3e. Besides C1'NH-O4, an HB is formed in the catechol moiety with adjacent $\mathrm{C}^{\prime \prime} \mathrm{OH}-\mathrm{O} 4$ ". The number and position of the hydrogen bonds play a major role in the stabilization of the molecule and consequently have an impact on its antioxidative capacity [43]. Careful analysis of the structures of the considered compounds showed that benzopyrone and phenyl rings were not in the planar conformation. The calculated dihedral angles $\mathrm{C}-\mathrm{N}-\mathrm{N}-\mathrm{C}$ were found in the interval between $74.71^{\circ}-76.51^{\circ}$ for all scrutinized compounds. These values clearly show that the examined compounds lose coplanarity to varying degrees. These results indicate the weakening of the electronic distribution within the compounds, which significantly affects their antioxidant activity.

\subsubsection{Bond Dissociation Energy}

The BDE values for $\mathrm{OH}$ and $\mathrm{NH}$ groups are known to be of particular importance for understanding the mechanism of free radical scavenging activity [44,45]. This means that a weak O-H or N-H bond has a rapid response and thus potential for antioxidative activity. The capacity of coumarin-hydroxybenzohydrazide derivatives to remove free radicals is generally related to the existence of $\mathrm{OH}$ and $\mathrm{NH}$ groups in a particular position on the core of coumarin-hydroxybenzohydrazide derivatives. Optimization of the geometry of radical species formed after homolytic cleavage of either $\mathrm{OH}$ or $\mathrm{NH}$ bonds for all coumarinhydroxybenzohydrazide derivatives is performed starting from the optimized geometry of neutral molecules. Removal of $\mathrm{H}$-atoms from the C2"-OH, C3"-OH, C4"-OH, and C7"-NH positions in coumarin-hydroxybenzohydrazide derivatives yields various radical species. 
For example, the radical species created by removing the $\mathrm{H}$-atom from the $\mathrm{C} 2$ "-OH group of $3 \mathbf{a}$ is called $3 \mathrm{aC}^{\prime \prime} \mathrm{O}^{\bullet}$. The remaining radical species are generated and named in the same way. It should be noted that the geometry optimization of free radical species was performed using the same theoretical model and in the same solvents as for the parent molecules.

The calculated BDE values for all coumarin-hydroxybenzohydrazide derivatives are shown in Table 3. From the calculated values, it can be seen that the smallest BDE values are obtained for the $\mathrm{C7}^{\prime \prime}-\mathrm{NH}$ position, in both solvents, for all investigated molecules, except in the case of compound 3e, where slightly lower BDE values are obtained for the $\mathrm{OH}$ group in the para position. Such BDE values for $3 \mathbf{e}$ are a consequence of catechol structure and the formation of intramolecular hydrogen bonds between both, adjacent $\mathrm{OH}$ groups and the resulting radicals with the adjacent $\mathrm{OH}$ group. In addition, the $\mathrm{BDE}$ values of the neighboring $\mathrm{OH}$ groups in $\mathbf{3} \mathbf{d}$ are somewhat higher, despite the fact that the groups are in $o$ - and $m$-positions.

Table 3. Thermodynamic parameters of antioxidant mechanism for investigated coumarin-hydroxybenzohydrazide derivatives in $\mathrm{kJ} \mathrm{moL}^{-1}$.

\begin{tabular}{|c|c|c|c|c|c|c|c|c|c|c|}
\hline \multirow{3}{*}{ Position } & \multicolumn{5}{|c|}{ BENZENE } & \multicolumn{5}{|c|}{ METHANOL } \\
\hline & \multirow{2}{*}{$\begin{array}{l}H A T \\
\text { BDE }\end{array}$} & \multicolumn{2}{|c|}{$S E T-P T$} & \multicolumn{2}{|c|}{ SPLET } & \multirow{2}{*}{$\begin{array}{l}\text { HAT } \\
\text { BDE }\end{array}$} & \multicolumn{2}{|c|}{ SET-PT } & \multicolumn{2}{|c|}{ SPLET } \\
\hline & & IP & PDE & PA & ETE & & IP & PDE & PA & ETE \\
\hline & & & & & $3 a$ & & & & & \\
\hline $\mathrm{C} 2 "-\mathrm{OH}$ & 404 & \multirow{3}{*}{714} & 123 & 446 & 391 & 373 & \multirow{3}{*}{552} & 19 & 191 & 380 \\
\hline $\mathrm{C}^{\prime \prime}-\mathrm{NH}$ & 383 & & 102 & 413 & 402 & 362 & & 7 & 161 & 398 \\
\hline & & & & & $3 b$ & & & & & \\
\hline $\mathrm{C} 4 "-\mathrm{OH}$ & 382 & \multirow{3}{*}{688} & 127 & 407 & 408 & 381 & \multirow{3}{*}{551} & 28 & 185 & 394 \\
\hline $\mathrm{C7}^{\prime \prime}-\mathrm{NH}$ & 348 & & 94 & 372 & 409 & 355 & & 3 & 156 & 398 \\
\hline & & & & & $3 c$ & & & & & \\
\hline $\mathrm{C}^{\prime \prime}-\mathrm{OH}$ & 377 & \multirow{3}{*}{693} & 118 & 422 & 388 & 377 & \multirow{3}{*}{528} & 47 & 200 & 375 \\
\hline C7"-NH & 348 & & 88 & 376 & 405 & 355 & & 25 & 158 & 395 \\
\hline & & & & & $3 d$ & & & & & \\
\hline $\mathrm{C} 2 "-\mathrm{OH}$ & 372 & \multirow{3}{*}{706} & 99 & 420 & 385 & 362 & \multirow{4}{*}{519} & 41 & 191 & 369 \\
\hline $\mathrm{C}^{\prime \prime}-\mathrm{OH}$ & 374 & & 101 & 430 & 376 & 365 & & 44 & 200 & 363 \\
\hline C7"-NH & 348 & & 75 & 343 & 438 & 355 & & 34 & 133 & 420 \\
\hline & & & & & $3 e$ & & & & & \\
\hline $\mathrm{C}^{\prime \prime}-\mathrm{OH}$ & 342 & \multirow{3}{*}{703} & 72 & 393 & 382 & 346 & \multirow{3}{*}{535} & 9 & 178 & 367 \\
\hline $\mathrm{C} 4 "-\mathrm{OH}$ & 344 & & 74 & 380 & 397 & 348 & & 11 & 168 & 378 \\
\hline C7"-NH & 346 & & 77 & 370 & 410 & 355 & & 19 & 154 & 399 \\
\hline
\end{tabular}

This is a consequence of better delocalization of the unpaired electron in the $3 \mathrm{eC}^{\prime \prime} \mathrm{O}^{\bullet}$ than in the $3 \mathrm{dC} 2{ }^{\prime \prime} \mathrm{O}^{\bullet}$ radical (Figure 1). However, it should be mentioned that BDE values for the position C7"-NH, calculated in benzene, are a little bit lower than those calculated in methanol are.

\subsubsection{Proton Affinity}

The heterolytic cleavage of N-H and O-H bonds leads to the formation of the corresponding anions. This process is considered to be the first step of the SPLET mechanistic pathway and is described by the thermodynamic parameter PA. The high calculated PA values indicate that the SPLET mechanism is not operative in non-polar conditions. On the other hand, PA values obtained in methanol were significantly lower, due to increased anion stabilization in polar solvents. This is a consequence of the fact that polar protic solvents stabilize anions via hydrogen bonding. The obtained results are presented in Table 3. By analyzing the PA values, it is clear that the abstraction of the proton from nitrogen is much easier than from an oxygen atom. The lowest PA value, found for $\mathbf{3 d}$, implies that this compound is the most reactive when operating following the SPLET mechanism. Such results are in good agreement with the results obtained in vitro. 


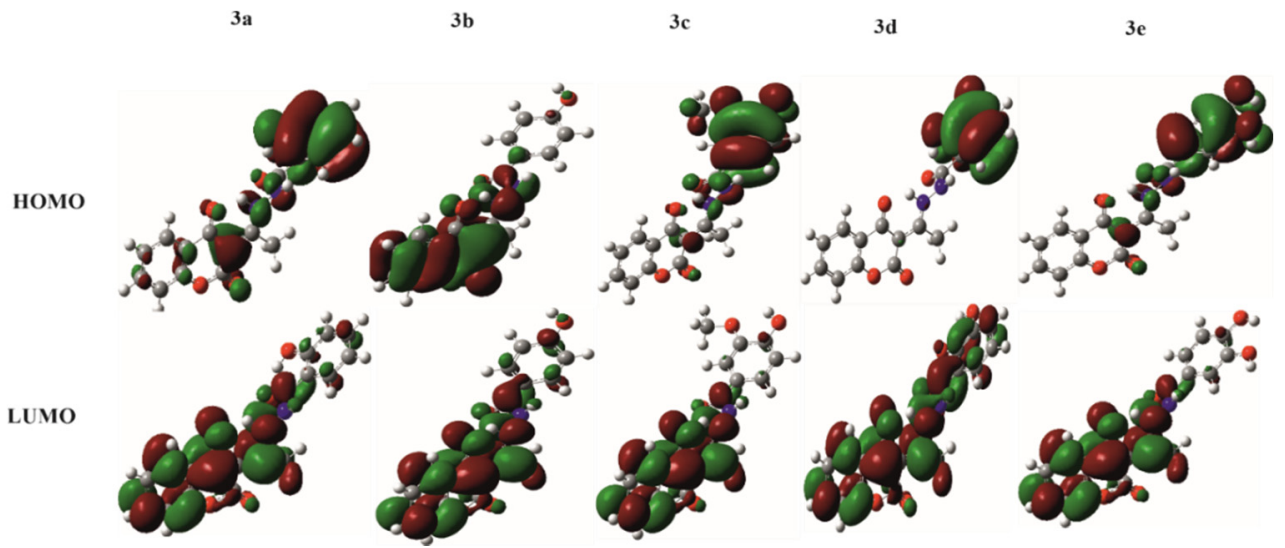

Figure 1. Frontier orbitals of the investigated compounds.

\subsubsection{Frontier Molecular Orbitals and HOMO-LUMO Gap}

Investigating the energies of the frontier molecular orbitals is very important for understanding the chemical behavior of tested compounds, because these orbitals usually take part in reactions. The ability of molecules with respect to electron donation or electron affinity can be determined using HOMO or LUMO energy values. The highest occupied molecular orbital (HOMO) usually indicates that the molecule is a good electron donor, and characterizes the susceptibility of the molecule to attack by electrophiles. The energy of the lowest unoccupied molecular orbital (LUMO) is related to electron affinity and describes the sensitivity of molecules toward nucleophile attack. The HOMO-LUMO gap $(\mathrm{H}-\mathrm{L})$, calculated as the energy difference between the HOMO and LUMO orbitals, is an important index of stability and chemical reactivity. A high value of $\mathrm{H}-\mathrm{L}$ implies high stability of molecules and lower reactivity in chemical reactions, while a low value of H-L implies low stability and higher molecular reactivity [22,33].

The frontier orbitals for the investigated compounds in methanol are shown in Figure 1 , and the frontier orbital energies, as well as H-L, are indicated in Table 4. The active site can be visually demonstrated by the distribution of the frontier orbital. Based on the results presented in Figure 1, it is obvious that the HOMO of almost all investigated compounds is mainly distributed in the aromatic ring of benzoyl-hydrazide, while LUMO is mainly assigned in the coumarin part of the molecule. The electron donation ability of a molecule can be determined by HOMO values; HOMO with high energy corresponds to a strong electron donation ability. From Table 4, it can be seen that 3c possesses the highest HOMO among all compounds, while 3 a possesses the lowest one. The H-L of $\mathbf{3 d}$, in methanol, is $6.39 \mathrm{eV}$, while for the least reactive $3 \mathbf{b}$ it is $6.74 \mathrm{eV}$. Values for the remaining compounds lie in the range of $0.35 \mathrm{eV}$. It should be noted that almost identical values are obtained for the $\mathrm{H}-\mathrm{L}$ energy in the nonpolar solvent. The lower the value of H-L, the more pronounced the antioxidant abilities of the molecules. The relatively low energy of H-L indicates that the scrutinized compounds could be a highly reactive system. The obtained values for the H-L are in accordance with the in vitro results obtained by the DPPH test (Table 2).

Table 4. The frontier orbital energy and energy gap (eV) of the investigated compounds.

\begin{tabular}{ccccccc}
\hline \multirow{2}{*}{ Ligand } & \multicolumn{3}{c}{ METHANOL } & \multicolumn{3}{c}{ BENZENE } \\
& HOMO & LUMO & HL Gap (eV) & HOMO & LUMO & HL Gap (eV) \\
\hline 3a & -8.09 & -1.41 & 6.68 & -8.10 & -1.37 & 6.72 \\
3b & -8.09 & -1.36 & 6.74 & -8.01 & -1.26 & 6.75 \\
3c & -7.80 & -1.35 & 6.45 & -7.85 & -1.26 & 6.59 \\
3d & -7.81 & -1.42 & 6.39 & -7.87 & -1.41 & 6.46 \\
3e & -7.86 & -1.36 & 6.50 & -7.94 & -1.28 & 6.66 \\
\hline
\end{tabular}


When the HOMO orbital is localized on the B ring (phenol/catechol part of the molecule), as is the case for the compounds $\mathbf{3 e}, \mathbf{3 d}$, and $\mathbf{3 c}$, values of the H-L, as well as the $E_{\mathrm{HOMO}}$, are higher than in the case of the compounds $\mathbf{3} \mathbf{a}$ and $\mathbf{3 b}$. Therefore, compounds $\mathbf{3 e}, \mathbf{3 d}$, and $\mathbf{3 c}$ are more reactive than compounds $\mathbf{3} \mathbf{a}$ and $\mathbf{3 b}$. The difference in HOMO distribution between $\mathbf{3 a}$ and $\mathbf{3 b}$ is a consequence of $\mathrm{HB}$ forming between $\mathrm{OH}$ group in position $\mathrm{C}^{\prime \prime}-\mathrm{OH}$ and carbonyl group in position $\mathrm{C7}^{\prime \prime}$. Besides the position of the $\mathrm{OH}$ group and its ability to form $\mathrm{HB}$, several electron-rich substituents on the B ring play an important part in HOMO and LUMO distribution, as well as the values of the H-L. As seen from Figure 1, HOMO tends to be localized on the part of the molecule with electron-rich substituents, because of the increased electron delocalization. This is why $\mathbf{3 c}$, $\mathbf{3 d}$, and $\mathbf{3 e}$ have HOMO distributed only over the B ring, which makes the HOMO orbital less stable, thus making the H-L smaller. Expectedly, compounds with a smaller HL-gap are more reactive towards free radical species.

The data presented in Table 4 suggest that compound $\mathbf{3 d}$ has the highest antioxidative potential since it has the lowest value of H-L.

\subsubsection{Ionization Potential}

Removal of free radicals can also be achieved by donating one electron from the parent compound to the free radical, which is followed by the formation of a radical cation. The ability of the investigated compound to donate an electron is associated with prolonged electron delocalization across the entire molecule. It is known that many natural products such as flavonoids, which have a high degree of $\pi$-delocalization, are more active as radical scavengers. The value that measures this ability is IP. The calculated IP values for the investigated compounds in methanol and benzene are given in Table 3.

Generally speaking, molecules with lower IP values are more easily engaged in radicalscavenging reactions $[46,47]$. All investigated compounds show mutually similar and high values for this thermodynamic parameter (Table 3). Based on the presented values for IP, it can be concluded that this mechanistic pathway is unlikely, and should be excluded from further discussion.

\subsection{Theoretical Assessment of Mechanisms of Antioxidative Action}

Based on the values of BDE, IP, PDE, PA, and ETE, the dominant mechanism of antioxidant action of coumarin-hydroxybenzohydrazide derivatives $\mathbf{3 a - e}$ can be assumed. The thermodynamically most preferable mechanism is the one with the lowest value for the parameter describing the first step. All thermodynamic parameters for the examined coumarin-hydroxybenzohydrazide derivatives 3a-e were calculated by applying the same level of theory in benzene and methanol as solvents (Table 3). The obtained values of thermodynamic parameters indicate that the good antioxidative activity of these compounds can be expected. It was found that PA values in methanol were considerably lower than the corresponding BDEs. This implies that SPLET is the predominant mechanism of antioxidant action in a polar environment. The obtained PA values suggest that compound 3d shows the highest antioxidative capacity, which is in good agreement with $\mathrm{IC}_{50}$ values (Table 2). On the other hand, the values of BDE and PA (Table 3) indicate the competition of HAT and SPLET mechanisms in a non-polar medium.

\subsection{Radicals and Anions of Investigated Compounds}

The potential antioxidative action of the investigated compounds requires homolytic and heterolytic bond cleavage between the hydrogen and heteroatom. This leads to the formation of corresponding radicals and anions. The relative stability of these chemical species depends on their ability for the delocalization of unpaired electrons or charges. Depending on their relative stability, it can be determined which functional group or position is the most likely to contribute to the antioxidant activity, i.e., to the ROS inactivation. According to the thermodynamic parameters presented in Table 3, radical species derived from NH groups are generally more stable than those formed by homolytic cleavage of 
the $\mathrm{OH}$ bond. This behavior can be explained by examining the radical structures of the investigated compounds presented in Figure 2. Radicals formed by removing hydrogen atoms from the nitrogen of the hydrazide group are more stable. The main reason for this lies in the fact that nitrogen atom rehybridizes from $\mathrm{sp}^{3}$ to $\mathrm{sp}^{2}$ hybrid, which causes the investigated compounds to become planar.

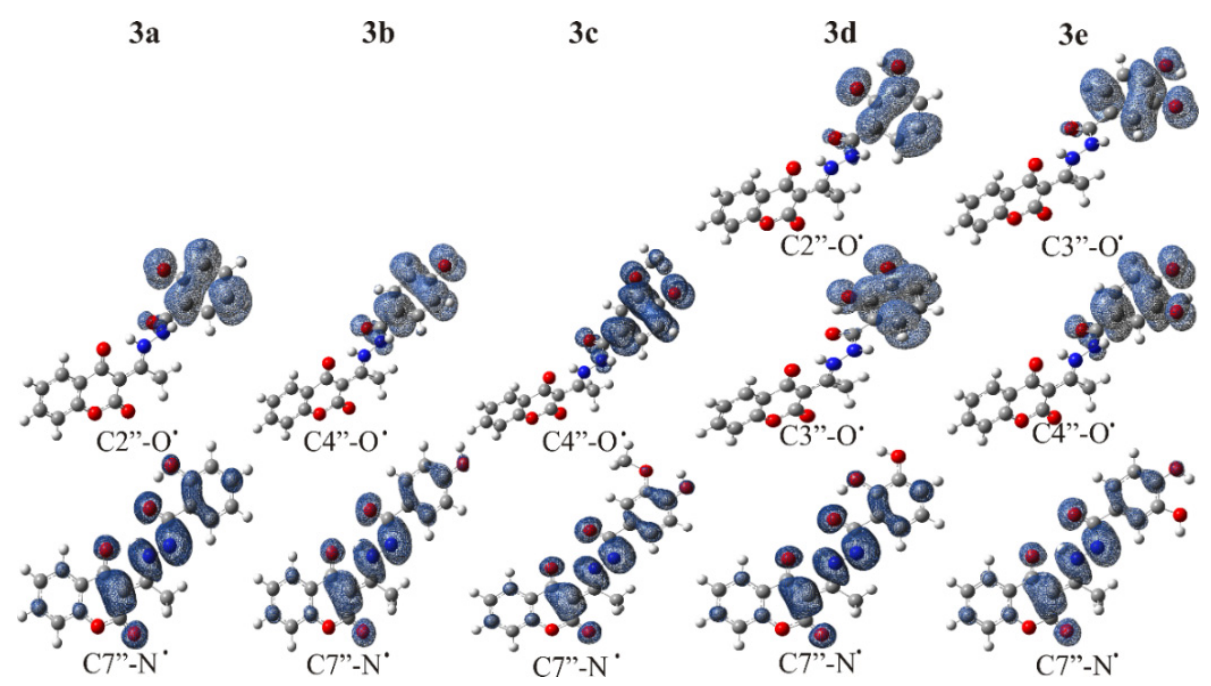

Figure 2. Spin density maps of the radicals obtained in the radical scavenging reactions of investigated compounds.

The planar conformation enables the delocalization of the spin over the whole molecule (Figure 2), and better delocalization leads to the higher radical stability of all investigated compounds. On the other hand, in cases where the antioxidant action is achieved through the $\mathrm{OH}$ group, the spin is delocalized only on the $\mathrm{B}$ ring of the molecule.

The maps of electrostatic potentials (ESP) of the investigated anions show that in the planar conformation, negative charge is better delocalized than in the non-planar one (Figure S18). As the atomic charges of ESP are important for understanding the second step of the SPLET mechanism, ESP maps of all coumarin hybrids were calculated to verify high electron density regions that can indicate the atoms responsible for the next step and, consequently, the electron transfer. Figure S17 shows the ESP maps of the tested compounds, while Figure S18 shows ESP maps of the corresponding anions.

It can be seen, from Figure S18, that a localized homogeneous negative surface (represented in red) is on the atom from which the single proton was abstracted. The best delocalization effect was found for the nitrogen atom anion in position $\mathrm{C7}^{\prime \prime}-\mathrm{N}^{-}$, which delocalizes its negative charge through the oxygen atom on the carbonyl group and the corresponding oxygen atoms on the B ring. Delocalization of this type of negative charge is presented in Figure 3.
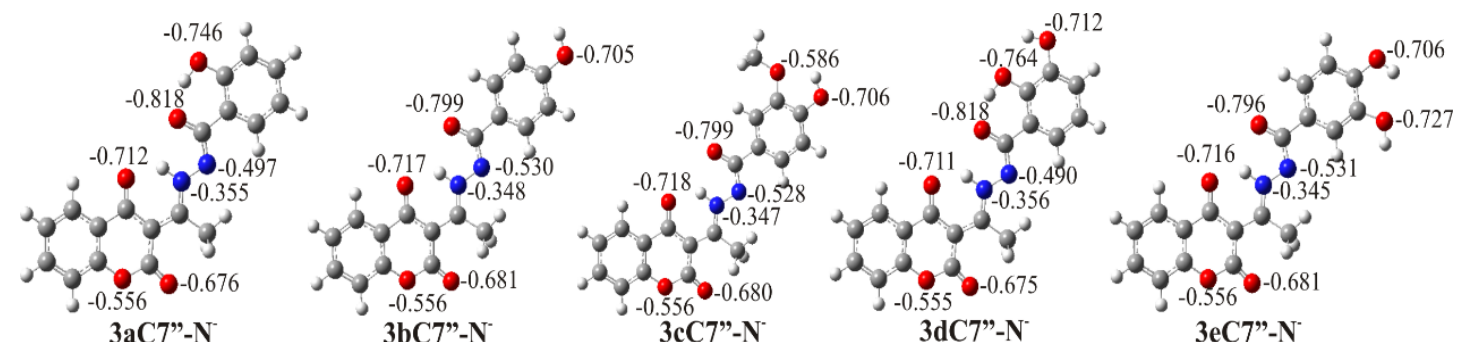

Figure 3. The NBO charge delocalization for anions obtained by proton abstraction from -NH group in position C7"-N for investigated compounds. 


\subsection{Radical Scavenging Activity against DPPH Radical}

The antioxidative capacity of the investigated coumarin-hydroxybenzohydrazide derivatives was examined by the DPPH test, and the results are presented in Table 2. Since the $\mathrm{IC}_{50}$ values represent the sample concentration required to inhibit $50 \%$ of DPPH radicals, thermodynamic calculation on possible inactivation of DPPH radical through already examined free radical scavenging mechanisms was performed. The potential mechanisms of free radical scavenging were discussed based on a change in enthalpies for reactions following HAT, SET-PT and SPLET mechanisms. The calculations were performed in methanol, simulating the environment in which the in vitro DPPH test was performed. The energy difference between the products and reactants of the reaction was used as the principal to assess whether the reaction can be expected to occur or not. The lowest value of thermodynamic parameters implies the preferability of the mechanistic pathway.

Analysis of the results presented in Table 5 exposes positive $\Delta H_{\text {IP }}$ values for reaction with all investigated compounds. This means that all the examined reactions of scavenging of DPPH radical via SET-PT are endergonic. The high values of $\Delta H_{\text {IP }}$ unequivocally indicate that the SET-PT mechanism can be neglected when scavenging of DPPH radical is discussed, which is consistent with the thermodynamic results presented in Table 3. Furthermore, the HAT and SPLET mechanisms will be considered possible mechanisms of scavenging the DPPH radical. Both HAT and SPLET mechanisms can be discussed as potential mechanisms of radical scavenging in methanol, since low positive values $(<50 \mathrm{~kJ} / \mathrm{moL})$ are obtained. The obtained values of $\Delta H_{\mathrm{BDE}}$ and $\Delta H_{\mathrm{PA}}$ for all examined compounds are similar and indicate endogenic reactions, except in the case of the radical, e.g., the anion in the C7"-NH position. Namely, in the C7"-NH position, negative values of $\Delta \boldsymbol{H}_{\mathrm{PA}}$ are obtained, implying an exergonic reaction. Based on this, it can be expected that DPPH radical in methanol will probably be scavenged following the SPLET mechanistic pathway. This hypothesis should be proven or annulled with the appropriate values of activation energies.

Table 5. Calculated parameters of radical scavenging activity for coumarin hybrids in $\mathrm{kJ} \mathrm{moL}^{-1}$.

\begin{tabular}{|c|c|c|c|c|c|}
\hline \multirow{2}{*}{ METHANOL } & \multirow{2}{*}{$\begin{array}{c}H A T \\
\Delta H_{\mathrm{BDE}}\end{array}$} & \multicolumn{2}{|c|}{ SET-PT } & \multicolumn{2}{|c|}{ SPLET } \\
\hline & & $\Delta H_{\mathrm{IP}}$ & $\Delta H_{\mathrm{PDE}}$ & $\Delta H_{\mathrm{PA}}$ & $\Delta H_{\mathrm{ETE}}$ \\
\hline \multicolumn{6}{|c|}{$3 a$} \\
\hline $\mathrm{C} 2 "-\mathrm{OH}$ & 47 & \multirow{3}{*}{201} & -142 & 50 & 7 \\
\hline $\mathrm{C}^{\prime \prime}-\mathrm{NH}$ & 27 & & -163 & 2 & 34 \\
\hline & & & & & \\
\hline $\mathrm{C} 4 "-\mathrm{OH}$ & 59 & \multirow{3}{*}{184} & -134 & 23 & 28 \\
\hline C7"-NH & 38 & & -159 & -6 & 29 \\
\hline & & & & & \\
\hline $\mathrm{C} 4 "-\mathrm{OH}$ & 50 & \multirow{3}{*}{161} & -115 & 38 & 3 \\
\hline C7"-NH & 24 & & -137 & -4 & 25 \\
\hline & & & & & \\
\hline $\mathrm{C}^{\prime \prime}-\mathrm{OH}$ & 34 & \multirow{3}{*}{152} & -118 & 38 & -4 \\
\hline $\mathrm{C} 2 "-\mathrm{OH}$ & 31 & & -121 & 29 & 0.1 \\
\hline $\mathrm{C}^{\prime \prime}-\mathrm{NH}$ & 24 & & -128 & -29 & 53 \\
\hline & & & & & \\
\hline $\mathrm{C} 4 "-\mathrm{OH}$ & 17 & \multirow{3}{*}{168} & -151 & 6 & 9 \\
\hline $\mathrm{C}^{\prime \prime}-\mathrm{OH}$ & 15 & & -152 & 16 & -1.8 \\
\hline $\mathrm{C}^{\prime \prime}-\mathrm{NH}$ & 25 & & -143 & -8 & 32 \\
\hline
\end{tabular}

The obtained experimental and theoretical results (Tables 2 and 5) suggest that $\mathbf{3 d}$ is more reactive than $3 \mathbf{e}$ against the $\mathrm{DPPH}$ radical. At the same time, $\mathrm{IC}_{50}$ values for $\mathbf{3 a}, \mathbf{3} \mathbf{b}$, and $3 c$ suggest that their activity is almost non-existent, while $\Delta H_{P A}$ values from Table 5 do not infer a significant difference between these three compounds and compound $\mathbf{3 e}$. This can be explained by the fact that compound $\mathbf{3 e}$, in comparison to compounds $\mathbf{3 a}, \mathbf{3} \mathbf{b}$, and $3 c$, has one $\mathrm{OH}$ group more, which allows a better chance of reacting with the free radical 
species. The results presented in Table 5 suggest that the mechanism of radical scavenging against DPPH radical is SPLET, following the experimental results.

\subsection{Potential Toxicology}

To find whether compounds were suitable to be used as antioxidants in food industry, potential toxicity was investigated. For this purpose, the Prediction of Toxicity of Chemicals (ProTox-II) webserver protocol was used [48]. The results of the potential toxicity are presented in Table 6 . To closely determine overall toxicity, investigated compounds are divided into six toxicity classes by the median lethal dose $\left(\mathrm{LD}_{50}\right)$. These toxicity classes are defined according to the globally harmonized system of classification and labelling of chemicals (GHS). Compounds from Class I are highly toxic and fatal if swallowed $\left(\mathrm{LD}_{50}<5 \mathrm{mg} / \mathrm{kg}\right.$ ). The Class II compounds' $\mathrm{LD}_{50}$ is found in the range between 5 and $50 \mathrm{mg} / \mathrm{kg}$, and these compounds are still considered fatal if swallowed. Class III compounds are considered toxic, but with no fatal consequences, with $\mathrm{LD}_{50}$ in between 50 $\mathrm{mg} / \mathrm{kg}$ and $300 \mathrm{mg} / \mathrm{kg}$. Class IV compounds are harmful if swallowed, with $\mathrm{LD}_{50}$ between $300 \mathrm{mg} / \mathrm{kg}$ and $2000 \mathrm{mg} / \mathrm{kg}$. Class $\mathbf{V}$ consist of compounds that may be harmful if swallowed $\left(2000 \mathrm{mg} / \mathrm{kg}<\mathrm{LD}_{50} \leq 5000 \mathrm{mg} / \mathrm{kg}\right.$ ), while Class VI contains compounds that are considered non-toxic, with $\mathrm{LD}_{50}>5000 \mathrm{mg} / \mathrm{kg}$.

Table 6. Predicted toxicity of the investigated compounds 3a-e with warfarin, esculetin, 4-hydroxy coumarin, quercetin, and ethanol as referent compounds.

\begin{tabular}{ccc}
\hline Compound: & Predicted Toxicity Class & Predicted LD $_{\mathbf{5 0}}(\mathbf{m g} / \mathbf{k g})$ \\
\hline 3a & Class V & 3000 \\
3b & Class IV & 1460 \\
3c & Class IV & 721 \\
3d & Class V & 3000 \\
3e & Class IV & 2000 \\
Warfarin & Class I & 2 \\
Esculetin & Class IV & 945 \\
4-hydroxy coumarin & Class IV & 2000 \\
Quercetin & Class III & 159 \\
Ethanol & Class V & 3450 \\
\hline
\end{tabular}

According to the results presented in Table 6, compounds 3a, 3d, and 3e show significantly lower potential toxicity than esculetin and quercetin, which are natural products found in plants with a wide range of commercial uses [49-51]. Additionally, compounds with the $\mathrm{OH}$ group in $\mathrm{C2}$ " position, i.e., $\mathbf{3 a}$ and $\mathbf{3 d}$, showed a significant decrease in potential toxicity in comparison with parent molecule, 4-hydroxy coumarin. Bearing in mind that $3 \mathbf{d}$ has shown excellent antioxidative properties, it is possible to consider it a potential supplement in the food industry, although experimental in vitro/in vivo studies are necessary for the definite conclusion.

\section{Conclusions}

Green synthesis of coumarin-hydroxybenzohydrazide derivatives by using a mixture of vinegar and ethanol as a catalyst and solvent is reported in this paper. This protocol provides isolation of pure products in moderate yield without any purification. The obtained compounds were structurally characterized by IR and NMR spectroscopy, and examined for their in vitro antioxidant activity. The results of the in vitro DPPH examination showed that two out of five of the investigated compounds, $3 \mathbf{d}$ and $3 \mathbf{e}$, expressed high antioxidant activity. It should be mentioned that especially compound $3 \mathrm{~d}$, with an activity slightly lower than the reference compounds NDGA and quercetin, acts as an excellent radical scavenger. In addition, the preferred radical scavenging pathways were theoretically investigated by the density functional theory approach. For that purpose, the values of various thermodynamic parameters, such as bond dissociation enthalpy, proton affinity, frontier molecular orbitals, HOMO-LUMO gap, and ionization potential were calculated. In silico 
calculations showed that HAT and SPLET reaction mechanisms are probable in non-polar and polar solvents, respectively. On the other hand, it was found that the SET-PT was not an operative mechanism in both solvents.

Supplementary Materials: The following are available online at https:/ / www.mdpi.com/article/10 $.3390 /$ antiox10071106/s1.

Author Contributions: Conceptualization, Z.S.M., M.R.A. and E.H.A.; methodology, Z.S.M., D.M.S., A.Ć. and E.H.A.; software, M.R.A.; validation, Z.S.M., V.S. and Z.D.P.; formal analysis, M.R.A. and J.D.M.; investigation, D.M.S. and E.H.A.; resources, V.S. and Z.D.P.; data curation, V.S. and J.D.M.; writing—original draft preparation, M.R.A., E.H.A.; writing—review and editing, Z.S.M., Z.D.P. and J.D.M.; visualization, D.M.S. and J.D.M.; supervision, Z.S.M.; project administration, D.M.S. and Z.D.P.; funding acquisition, Z.S.M. All authors have read and agreed to the published version of the manuscript.

Funding: This research was funded by the Serbian Ministry of Education, Science, and Technological Development (Agreement Nos 451-03-09/2021-14/200378; 451-03-09/2021-14/200122 and 451-039/2021-14/200146).

Institutional Review Board Statement: Not applicable.

Informed Consent Statement: Not applicable.

Data Availability Statement: Data is contained within the article and supplementary material.

Conflicts of Interest: The authors declare no conflict of interest.

\section{References}

1. Liu, Y.; Fiskum, G.; Schubert, D. Generation of reactive oxygen species by the mitochondrial electron transport chain. J. Neurochem. 2002, 80, 780-787. [CrossRef] [PubMed]

2. Martinez-Cayuela, M. Oxygen free radicals and human disease. Biochimie 1995, 77, 147-161. [CrossRef]

3. Valko, M.; Leibfritz, D.; Moncol, J.; Cronin, M.T.; Mazur, M.; Telser, J. Free radicals and antioxidants in normal physiological functions and human disease. Int. J. Biochem. Cell Biol. 2007, 39, 44-84. [CrossRef] [PubMed]

4. Sadeer, N.B.; Llorent-Martínez, E.J.; Bene, K.; Mahomoodally, M.F.; Mollica, A.; Sinan, K.I.; Zengin, G. Chemical profiling, antioxidant, enzyme inhibitory and molecular modelling studies on the leaves and stem bark extracts of three African medicinal plants. J. Pharm. Biomed. Anal. 2019, 174, 19-33. [CrossRef] [PubMed]

5. Mollica, A.; Costante, R.; Fiorito, S.; Genovese, S.; Stefanucci, A.; Mathieu, V.; Epifano, F. Synthesis and anti-cancer activity of naturally occurring 2, 5-diketopiperazines. Fitoterapia 2014, 98, 91-97. [CrossRef] [PubMed]

6. Uysal, A.; Ozer, O.Y.; Zengin, G.; Stefanucci, A.; Mollica, A.; Picot-Allain, C.M.N.; Mahomoodally, M.F. Multifunctional approaches to provide potential pharmacophores for the pharmacy shelf: Heracleum sphondylium L. subsp. ternatum (Velen.) Brummitt. Comput. Biol. Chem. 2019, 78, 64-73. [CrossRef]

7. Kirsch, G.; Abdelwahab, A.B.; Chaimbault, P. Natural and synthetic coumarins with effects on inflammation. Molecules 2016, 21, 1322. [CrossRef] [PubMed]

8. Bansal, Y.; Sethi, P.; Bansal, G. Coumarin: A potential nucleus for anti-inflammatory molecules. Med. Chem. Res. 2013, 22, 3049-3060. [CrossRef]

9. Hassan, M.Z.; Osman, H.; Ali, M.A.; Ahsan, M.J. Therapeutic potential of coumarins as antiviral agents. Eur. J. Med. Chem. 2016, 123, 236-255. [CrossRef]

10. Thakur, A.; Singla, R.; Jaitak, V. Coumarins as anticancer agents: A review on synthetic strategies, mechanism of action and SAR studies. Eur. J. Med. Chem. 2015, 101, 476-495. [CrossRef]

11. de Souza, L.G.; Rennó, M.N.; Figueroa-Villar, J.D. Coumarins as cholinesterase inhibitors: A review. Chem.-Biol. Interact. 2016, 254, 11-23. [CrossRef] [PubMed]

12. A Garro, H.; R Pungitore, C. Coumarins as potential inhibitors of DNA polymerases and reverse transcriptases. Searching new antiretroviral and antitumoral drugs. Curr. Drug Discov. Technol. 2015, 12, 66-79. [CrossRef] [PubMed]

13. Emami, S.; Dadashpour, S. Current developments of coumarin-based anti-cancer agents in medicinal chemistry. Eur. J. Med. Chem. 2015, 102, 611-630. [CrossRef]

14. Zhang, L.; Xu, Z. Coumarin-containing hybrids and their anticancer activities. Eur. J. Med. Chem. 2019, 181, 111587. [CrossRef]

15. Menezes, J.C.; Diederich, M. Translational role of natural coumarins and their derivatives as anticancer agents. Future Med. Chem. 2019, 11, 1057-1082. [CrossRef]

16. Kotali, A.; Nasiopoulou, D.A.; Harris, P.A.; Helliwell, M.; Joule, J.A. Transformation of a hydroxyl into an acyl group on $\alpha$-pyrone ring: A novel route to 3, 4-diacylcoumarins. Tetrahedron 2012, 68, 761-766. [CrossRef] 
17. Kotali, A.; Nasiopoulou, D.A.; Tsoleridis, C.A.; Harris, P.A.; Kontogiorgis, C.A.; Hadjipavlou-Litina, D.J. Antioxidant Activity of 3-[N-(Acylhydrazono) ethyl]-4-hydroxy-coumarins. Molecules 2016, 21, 138. [CrossRef]

18. Govindaiah, P.; Dumala, N.; Mattan, I.; Grover, P.; Prakash, M.J. Design, synthesis, biological and in silico evaluation of coumarin-hydrazone derivatives as tubulin targeted antiproliferative agents. Bioorg. Chem. 2019, 91, 103143. [CrossRef] [PubMed]

19. Avdović, E.H.; Petrović, I.P.; Stevanović, M.J.; Saso, L.; Dimitrić Marković, J.M.; Filipović, N.D.; Živić, M.Ž.; Cvetić Antić, T.N.; Žižić, M.V.; Todorović, N.V.; et al. Synthesis and Biological Screening of New 4-Hydroxycoumarin Derivatives and Their Palladium (II) Complexes. Oxidative Med. Cell. Longev. 2021, 2021, 8849568. [CrossRef]

20. Milovanović, V.M.; Petrović, Z.D.; Novaković, S.; Bogdanović, G.A.; Petrović, V.P.; Simijonović, D. Green synthesis of benzamidedioxoisoindoline derivatives and assessment of their radical scavenging activity-Experimental and theoretical approach. Tetrahedron 2020, 76, 131456. [CrossRef]

21. Kontogiorgis, C.; Hadjipavlou-Litina, D. Biological evaluation of several coumarin derivatives designed as possible antiinflammatory/antioxidant agents. J. Enzym. Inhib. Med. Chem. 2003, 18, 63-69. [CrossRef] [PubMed]

22. Dimić, D.; Milenković, D.; Marković, J.D.; Marković, Z. Antiradical activity of catecholamines and metabolites of dopamine: Theoretical and experimental study. Phys. Chem. Chem. Phys. 2017, 19, 12970-12980. [CrossRef] [PubMed]

23. Prihantini, A.I.; Tachibana, S.; Itoh, K. Antioxidant active compounds from elaeocarpussylvestris and their relationship between structure and activity. Procedia Environ. Sci. 2015, 28, 758-768. [CrossRef]

24. Frisch, M.J.; Trucks, G.W.; Schlegel, H.B. Gaussian 09 (Revision E. 01); Gaussian Inc.: Wallingford, CT, USA, 2013.

25. Zhao, Y.; Truhlar, D.G. The M06 suite of density functionals for main group thermochemistry, thermochemical kinetics, noncovalent interactions, excited states, and transition elements: Two new functionals and systematic testing of four M06-class functionals and 12 other functionals. Theor. Chem. Acc. 2008, 120, 215-241.

26. Walker, M.; Harvey, A.J.; Sen, A.; Dessent, C.E. Performance of M06, M06-2X, and M06-HF density functionals for conformationally flexible anionic clusters: M06 functionals perform better than B3LYP for a model system with dispersion and ionic hydrogenbonding interactions. J. Phys. Chem. A 2013, 117, 12590-12600. [CrossRef]

27. Takano, Y.; Houk, K.N. Benchmarking the conductor-like polarizable continuum model (CPCM) for aqueous solvation free energies of neutral and ionic organic molecules. J. Chem. Theory Comput. 2005, 1, 70-77. [CrossRef] [PubMed]

28. Marković, Z. Study of the mechanisms of antioxidative action of different antioxidants. J. Serb. Soc. Comput. Mech. 2016, 10, 135-150. [CrossRef]

29. Milenković, D.A.; Dimić, D.S.; Avdović, E.H.; Amić, A.D.; Marković, J.M.D.; Marković, Z.S. Advanced oxidation process of coumarins by hydroxyl radical: Towards the new mechanism leading to less toxic products. Chem. Eng. J. 2020, $395,124971$. [CrossRef]

30. Galano, A.; Mazzone, G.; Alvarez-Diduk, R.; Marino, T.; Alvarez-Idaboy, J.R.; Russo, N. Food antioxidants: Chemical insights at the molecular level. Annu. Rev. Food Sci. Technol. 2016, 7, 335-352. [CrossRef]

31. Galano, A. Free radicals induced oxidative stress at a molecular level: The current status, challenges and perspectives of computational chemistry based protocols. J. Mex. Chem. Soc. 2015, 59, 231-262. [CrossRef]

32. Wang, G.; Xue, Y.; An, L.; Zheng, Y.; Dou, Y.; Zhang, L.; Liu, Y. Theoretical study on the structural and antioxidant properties of some recently synthesised 2, 4, 5-trimethoxy chalcones. Food Chem. 2015, 171, 89-97. [CrossRef]

33. Wang, L.; Yang, F.; Zhao, X.; Li, Y. Effects of nitro-and amino-group on the antioxidant activity of genistein: A theoretical study. Food Chem. 2019, 275, 339-345. [CrossRef]

34. Marković, Z.; Tošović, J.; Milenković, D.; Marković, S. Revisiting the solvation enthalpies and free energies of the proton and electron in various solvents. Comput. Theor. Chem. 2016, 1077, 11-17. [CrossRef]

35. Avdović, E.H.; Stojković, D.L.; Jevtić, V.V.; Kosić, M.; Ristić, B.; Harhaji-Trajković, L.; Vukić, M.; Vuković, N.; Marković, Z.S.; Potočňák, I.; et al. Synthesis, characterization and cytotoxicity of a new palladium (II) complex with a coumarin-derived ligand 3-(1-(3-hydroxypropylamino) ethylidene) chroman-2, 4-dione. Crystal structure of the 3-(1-(3-hydroxypropylamino) ethylidene)-chroman-2, 4-dione. Inorg. Chim. Acta 2017, 466, 188-196. [CrossRef]

36. Dimić, D.S.; Marković, Z.S.; Saso, L.; Avdović, E.H.; Đorović, J.R.; Petrović, I.P.; Stanisavljević, D.D.; Stevanović, M.J.; Potočňák, I.; Samol'ová, E.; et al. Synthesis and Characterization of 3-(1-((3, 4-Dihydroxyphenethyl) amino) ethylidene)-chroman-2, 4-dione as a Potential Antitumor Agent. Oxidative Med. Cell. Longev. 2019, 2019, 2069250. [CrossRef] [PubMed]

37. Avdović, E.H.; Milenković, D.; Marković, J.M.D.; Đorović, J.; Vuković, N.; Vukić, M.D.; Jevtić, V.V.; Trifunović, S.R.; Potočňák, I.; Marković, Z. Synthesis, spectroscopic characterization (FT-IR, FT-Raman, and NMR), quantum chemical studies and molecular docking of 3-(1-(phenylamino) ethylidene)-chroman-2, 4-dione. Spectrochim. Acta Part A Mol. Biomol. Spectrosc. 2018, 195, 31-40. [CrossRef] [PubMed]

38. Vinson, J.A.; Su, X.; Zubik, L.; Bose, P. Phenol antioxidant quantity and quality in foods: Fruits. J. Agric. Food Chem. 2001, 49, 5315-5321. [CrossRef] [PubMed]

39. Foti, M.C. Use and Abuse of the DPPH• Radical. J. Agric. Food Chem. 2015, 63, 8765-8776. [CrossRef] [PubMed]

40. Foti, M.C.; Johnson, E.R.; Vinqvist, M.R.; Wright, J.S.; Barclay, L.R.C.; Ingold, K.U. Naphthalene diols: A new class of antioxidants intramolecular hydrogen bonding in catechols, naphthalene diols, and their aryloxyl radicals. J. Org. Chem. 2002, 67, 5190-5196. [CrossRef]

41. Bendary, E.; Francis, R.R.; Ali, H.M.G.; Sarwat, M.I.; El Hady, S. Antioxidant and structure-activity relationships (SARs) of some phenolic and anilines compounds. Ann. Agric. Sci. 2013, 58, 173-181. [CrossRef] 
42. Simijonović, D.; Petrović, Z.D.; Milovanović, V.M.; Petrović, V.P.; Bogdanović, G.A. A new efficient domino approach for the synthesis of pyrazolyl-phthalazine-diones. Antiradical activity of novel phenolic products. RSC Adv. 2018, 8, 16663-16673. [CrossRef]

43. Cornard, J.P.; Boudet, A.C.; Merlin, J.C. Theoretical investigation of the molecular structure of the isoquercitrin molecule. J. Mol. Struct. 1999, 508, 37-49. [CrossRef]

44. Sadasivam, K.; Kumaresan, R. Antioxidant behavior of mearnsetin and myricetin flavonoid compounds-A DFT study. Spectrochim. Acta Part A Mol. Biomol. Spectrosc. 2011, 79, 282-293. [CrossRef] [PubMed]

45. Vagánek, A.; Rimarčík, J.; Dropková, K.; Lengyel, J.; Klein, E. Reaction enthalpies of OH bonds splitting-off in flavonoids: The role of non-polar and polar solvent. Comput. Theor. Chem. 2014, 1050, 31-38. [CrossRef]

46. Petrović, Z.D.; Đorović, J.; Simijonović, D.; Petrović, V.P.; Marković, Z. Experimental and theoretical study of antioxidative properties of some salicylaldehyde and vanillic Schiff bases. RSC Adv. 2015, 5, 24094-24100. [CrossRef]

47. Zheng, Y.; An, L.; Dou, Y.; Liu, Y. Density functional theory study of the structure-antioxidant activity of polyphenolic deoxybenzoins. Food Chem. 2014, 151, 198-206.

48. Banerjee, P.; Eckert, A.O.; Schrey, A.K.; Preissner, R. ProTox-II: A webserver for the prediction of toxicity of chemicals. Nucleic Acids Res. 2018, 46, W257-W263. [CrossRef]

49. Gansukh, E.; Nile, A.; Kim, D.H.; Oh, J.W.; Nile, S.H. New insights into antiviral and cytotoxic potential of quercetin and its derivatives-a biochemical perspective. Food Chem. 2021, 334, 127508. [CrossRef]

50. Keizo, S.; Hiromichi, O.; Shigeru, A. Selective inhibition of platelet lipoxygenase by esculetin. Biochim. Biophys. Acta (BBA)-Lipids Lipid Metab. 1982, 713, 68-72. [CrossRef]

51. Milanović, Ž.B.; Antonijević, M.R.; Amić, A.D.; Avdović, E.H.; Dimić, D.S.; Milenković, D.A.; Marković, Z.S. Inhibitory activity of quercetin, its metabolite, and standard antiviral drugs towards enzymes essential for SARS-CoV-2: The role of acid-base equilibria. RSC Adv. 2021, 11, 2838-2847. [CrossRef] 